\title{
Evaluation of hepatic lipogenesis and antioxidant status of broiler chickens fed mountain celery
}

\author{
Behnam Ahmadipour ${ }^{1}$, Hossein Hassanpour ${ }^{2}$ and Fariborz Khajali ${ }^{1 *}$ (D)
}

\begin{abstract}
Background: Fatness is an unwanted side effect of genetic selection in broiler chickens. In this study, we introduce mountain celery powder as a feed supplement to suppress lipogenesis and improve antioxidant status in broiler chickens. Male broiler chicks (Ross 308) were fed a control diet or a diet that includes mountain celery (MC) at 7.5 $\mathrm{gkg}^{-1}$ over 42 days.

Results: Body weight gain and feed conversion ratio significantly $(P<0.05)$ improved in chicks fed MC. A highly significant down-regulation of genes involved in hepatic lipogenesis including acetyl CoA carboxylase (ACC), fatty acid synthase (FAS), malic enzyme (ME), and lipoprotein lipase (LPL) was observed in the liver of chickens fed MC. These birds, however, had greater compensatory upregulation in antioxidative genes SOD1 and catalase in the liver compared to the birds that received the control diet. Birds received $M C$ had significantly lower level of lipid peroxidation $(1.59 \mu \mathrm{mol} / \mathrm{L}$ serum malondialdehyde) compared to birds from the control group $(3.57 \mu \mathrm{mol} / \mathrm{L} ; P=0$. 0024). Birds fed $M C$ had significantly $(P<0.05)$ lower circulatory concentrations of triacylglycerols, cholesterol, and LDL but higher concentrations of HDL. Relative liver weight and abdominal fat deposition were significantly reduced by feeding $M C$.

Conclusions: It can be concluded that feeding birds MC significantly suppresses hepatic lipogenesis by downregulating key hepatic lipogenic enzyme genes and boosts antioxidant capacity by up-regulating hepatic antioxidantive genes.
\end{abstract}

Keywords: Antioxidant, Chicken, Celery, Hepatic lipogenesis

\section{Background}

Over the past several decades, intensive genetic selection in broiler chickens for rapid growth has led to their extraordinarily high growth rate. From 1957 to 2005, the body weight of broilers experienced a four-fold increase with a compounded annual growth rate of $3.30 \%$. Concurrently, the 42-day feed conversion ratio (FCR) of chickens decreased by $2.55 \%$ each year over the same period [1]. The main side effect of such enormous growth rate is excessive fat accumulation in the body [2]. Modern broilers tend to mature more quickly and begin depositing fat at an earlier age. The chicken meat industry now faces the challenge of controlling excessive

\footnotetext{
*Correspondence: khajali@agr.sku.ac.ir

'Department of Animal Science, Shahrekord University, Shahrekord

88186-34141, Iran

Full list of author information is available at the end of the article
}

fat. Body fat in broiler chickens are generally not physiologically essential for body functions but impose a heavy burden on the antioxidant system [3] as majority of the fat is unsaturated, which is susceptible to oxidation [4]. Lipid peroxidation is a major cause of poor food quality and generation of off-odours and off-flavours. The incorporation of antioxidants is the most effective way to control the rate and extent of lipid peroxidation [5]. Therefore, dietary antioxidants in chickens play a pivotal role in protecting unsaturated fats as well as the bird's body during digestion and metabolism, thereby the producion of high-quality meat.

Mountain celery (MC; Kelussia odoratissima; Umbelliferae family) is a rich source of polyphenols and flavonoids, and has antihyperlipidemic and antioxidant properties [6,7]. Mountain celery is a self-growing plant, growing up to $200 \mathrm{~cm}$ in height and is found exclusively 
in Iran. Flavonoids and polyphenols are strong natural antioxidants with lipid-lowering capacity $[5,8]$. The essential oil of MC is also a rich source of phthalides (37.3\% of total bioactive components) [9], which are reported to be hypolipidemic, hypoglycemic, hypotensive, and antioxidant. The antioxidant potency of $\mathrm{MC}$ is has previously been described as comparable to $\alpha$-tocopherol and butylated hydroxytoluene (BHT) [10]. Feeding MC to broiler chickens at 5 and $7.5 \mathrm{gkg}^{-1}$ resulted in a significant improvement in growth performance and was associated with lower rate of mortality from right ventricular hypertrophy [11]. Muscle relaxing and sedative effects of MC have been reported in mice [12]. The present study aimed to investigate antihyperlipidemic and antioxidant effects of $\mathrm{MC}$ in broiler chickens.

\section{Methods}

\section{Birds and experimental facility}

The experiment was conducted at the Poultry Research Center of Shahrekord University, Shahrekord, Iran (altitude $2100 \mathrm{~m}$ ) in accordance to the recommendations of the Guide for the Care and Use Committee of Shahrekord University. All procedures were conducted in accordance with guidelines set out by Directive 2010/63/ EU in Europe, and were approved by the Ethical Committee of Shahrekord University Research Council.

A total of 250 day-old male broilers (Ross 308; average body weight: $44.5 \mathrm{~g} \pm 1.25$ ) were obtained from Behjoojeh Co., Shahrekord, Iran. A total of 200 chicks within a range of 43 to $47 \mathrm{~g}$ (i.e within $\pm 2 \mathrm{SD}$ ) were randomly selected and assigned to 10 pens, each with 20 chicks. All pens had similar initial weights. Five of these pens were randomly assigned to each treatment. No statistical power calculation was conducted prior to the study. The sample size was based on our previous experience with similar design. All pens were equipped with a bell dinker and trough feeder. All chicks were allowed free access to feed and water and were provided with 23 L:1D lighting program throughout the trial. The house temperature was conformed to the strain recommendations.

\section{Treatments}

A control diet based on corn and soybean meal was formulated according to the NRC recommendations [13] for the starting ( 1 to $3 \mathrm{wk}$. of age) and growing ( 3 to $6 \mathrm{wk}$. of age) stages (Table 1). The experimental diet was prepared by substituting wheat bran with $7.5 \mathrm{gkg}^{-1} \mathrm{MC}$, a concentration of MC that has previously been described as the optimal level for broiler chickens [11]. Diets were provided in mash form. Mountain celery (the leaves and shoots) were cut, air-dried, and ground for use in the experimental diets. Chemical composition of the samples as $\mathrm{gkg}^{-1}$ DM include: protein 90 , dietary fiber 75 , calcium 18 , phosphorous 6 , sodium 0.4 , chloride 2.8 , potassium
20, polyphenols 102, and flavonoids 12.2 . The investigators were blinded to group allocation during the farm trial and laboratory analyses.

\section{Measurements}

Following the procedures established by the Association of Official Analytical Chemists (AOAC) [14], the experimental diets were analyzed for crude protein (Method 976.06), crude fiber (Method 978.10), calcium (Method 910.01), phosphorous (Method 966.01), sodium (Method 929.03), chloride (Method 915.01), and potassium (Method 956.01). The total phenolic content was determined in MC using the Folin-Ciocalteu method. In brief, $0.5 \mathrm{ml}$ of each sample was mixed with $2.5 \mathrm{ml}$ of FolinCiocalteu's phenol reagent and kept for $5 \mathrm{~min}$ at $37{ }^{\circ} \mathrm{C}$. Then, $2 \mathrm{ml}$ of saturated $\mathrm{Na}_{2} \mathrm{CO}_{3}(7.5 \%)$ was added and the mixture was brought up to $10 \mathrm{ml}$ using deionized-distilled water. The mixture was maintained at room temperature in the dark for 120 min before measuring its absorbance at $765 \mathrm{~nm}$ against a reagent blank. Gallic acid equivalent (GAE) was used as the reference standard and total phenolic content was expressed as mg of GAE per gram of each essential oil on the dry basis. Total flavonoid content was measured using the aluminum chloride colorimetric assay. An aliquot $(1 \mathrm{ml})$ of sample extracts or quercetin standard solutions $(20,40,60,80$ and $100 \mu \mathrm{g} / \mathrm{ml})$ was added to a $10 \mathrm{ml}$ volumetric flask containing $4 \mathrm{ml}$ of distilled water. Then, $0.30 \mathrm{ml}$ of $5 \% \mathrm{NaNO}_{2}$ was added, followed by the addition of $0.3 \mathrm{ml}$ of $10 \% \mathrm{AlCl}_{3}$ after $5 \mathrm{~min}$. Subsequently, $2 \mathrm{ml}$ of $1 \mathrm{M} \mathrm{NaOH}$ was added and the volume was brought up to $10 \mathrm{ml}$ with distilled water. The absorbance was measured against a blank at $510 \mathrm{~nm}$. The total flavonoid content was expressed as mg quercetin equivalents.

Body weight gain and feed intake were recorded and feed conversion ration (FCR) was calculated for the 1- to 21-day, 21- to 42-day, and 1- to 42-day periods. At 42 days of age, 10 birds per treatment were selected for blood collection and processing. The selected birds had body weights within $\sim 5 \%$ of the average pen body weight. Blood samples $(3 \mathrm{~mL})$ were collected from the brachial vein and centrifuged at $2500 \times \mathrm{g}$ for $10 \mathrm{~min}$ to obtain serum for the determination of cholesterol, triglycerides (TAG), low-density lipoproteins (LDL), high-density lipoproteins (HDL) and malondialdehyde (MDA). Total cholesterol, TAG, LDL, and HDL were measured using commercial laboratory kits following the manufacturer's manuals (Pars Azmoon Kits; Pars Azmoon, Tehran, Iran). Serum MDA concentration, a biomarker of lipid peroxidation, was assayed following the method of Nair and Turner [15]. An aliquot of blood was also obtained on glass slides to prepare a blood smear to determine differential leukocyte count. The blood was stained using the May-Grunwald and Giemsa protocol, and 100 leukocytes, 
Table 1 Composition of the basal diet to which mountain celery (MC) added for broiler chickens during starter (1-21 days) and grower (22-42 days) stages

\begin{tabular}{|c|c|c|c|c|}
\hline Item (\% unless noted) & Starter (Control) & Starter (MC diet) & Grower (Control) & Grower (MC diet) \\
\hline Corn & 46.85 & 46.85 & 55.75 & 55.75 \\
\hline Soybean meal (44\% CP) & 37.50 & 37.50 & 32.90 & 32.90 \\
\hline Fish meal $(60 \%$ CP) & 3.65 & 3.65 & 1.00 & 1.00 \\
\hline Soy oil & 7.50 & 7.50 & 6.00 & 6.00 \\
\hline Dicalcium phosphate & 1.30 & 1.30 & 1.20 & 1.20 \\
\hline Oyster shell & 1.45 & 1.45 & 1.50 & 1.50 \\
\hline Salt & 0.35 & 0.35 & 0.30 & 0.30 \\
\hline DL-Methionine & 0.15 & 0.15 & 0.10 & 0.10 \\
\hline L-Lysine & - & - & - & - \\
\hline Mineral supplement ${ }^{\mathrm{a}}$ & 0.25 & 0.25 & 0.25 & 0.25 \\
\hline Vitamin supplement ${ }^{\mathrm{b}}$ & 0.25 & 0.25 & 0.25 & 0.25 \\
\hline Wheat bran ${ }^{c}$ & 0.75 & - & 0.75 & - \\
\hline Mountain celery & - & 0.75 & - & 0.75 \\
\hline \multicolumn{5}{|l|}{ Calculated composition } \\
\hline AMEn (kcal/kg) & 3200 & 3200 & 3200 & 3200 \\
\hline $\mathrm{CP}$ & 23 & 23 & 20.00 & 20.00 \\
\hline Met & 0.50 & 0.50 & 0.40 & 0.40 \\
\hline Met + Cys & 0.85 & 0.85 & 0.75 & 0.75 \\
\hline Lys & 1.30 & 1.30 & 1.08 & 1.08 \\
\hline Thr & 1.05 & 1.05 & 0.93 & 0.93 \\
\hline $\operatorname{Arg}$ & 1.50 & 1.50 & 1.31 & 1.31 \\
\hline $\mathrm{Ca}$ & 1.03 & 1.03 & 0.90 & 0.90 \\
\hline Available P & 0.46 & 0.46 & 0.36 & 0.36 \\
\hline $\mathrm{Na}$ & 0.18 & 0.18 & 0.16 & 0.16 \\
\hline $\mathrm{Cl}$ & 0.27 & 0.27 & 0.29 & 0.29 \\
\hline K & 0.91 & 0.91 & 0.92 & 0.92 \\
\hline $\mathrm{Na}+\mathrm{K}-\mathrm{Cl}(\mathrm{mEq} / \mathrm{kg})$ & 233 & 233 & 236 & 236 \\
\hline
\end{tabular}

Provided the following per kilogram of diet: vitamin A (trans retinyl acetate), $3600 \mathrm{IU}$; vitamin D3 (cholecalciferol), $800 \mathrm{IU}$; vitamin E (dl-a-tocopheryl acetate), $7.2 \mathrm{mg}$; vitamin K3, $1.6 \mathrm{mg}$; thiamine, $0.72 \mathrm{mg}$; riboflavin, $3.3 \mathrm{mg}$; niacin, $0.4 \mathrm{mg}$; pyridoxin, $1.2 \mathrm{mg}$; cobalamine, $0.6 \mathrm{mg}$; folicacid, $0.5 \mathrm{mg}$; choline chloride, $200 \mathrm{mg}$ bProvided the following per kilogram of diet: $\mathrm{Mn}$ (from MnSO4 H2O), $40 \mathrm{mg} ; \mathrm{Zn}$ (from ZnO), 40 mg; Fe (from FeSO4 7H2O), $20 \mathrm{mg}$; $\mathrm{Cu}$ (fromCuSO4 5H2O), $4 \mathrm{mg}$; [ from $\mathrm{Ca}(\mathrm{IO} 3) 2 \mathrm{H} 2 \mathrm{O}$ ], $0.64 \mathrm{mg}$; Se (from sodium selenite), $0.08 \mathrm{mg}$

c mountain celery powder was replaced for wheat bran to provide the level of $7.5 \mathrm{~g} / \mathrm{kg}$

including granular (heterophils) and nongranular (lymphocytes) were counted to calculate the heterophil to lymphocyte ratio (H:L). All chemical reagents were obtained from Sigma-Aldrich Co. (Sigma-Aldrich Co., St. Louis, MO, USA).

After collecting blood, the birds were euthanized by $\mathrm{CO}_{2}$ inhalation and we collected live body weight, liver weight, and abdominal fat deposition. The livers were harvested and immediately frozen in liquid nitrogen and stored at $-70{ }^{\circ} \mathrm{C}$ for RNA analyses.

\section{Quantitative real-time PCR analysis}

Total RNA was extracted from the liver using RNX-Plus reagent (Sinaclon Bioscience, Tehran, Iran) and homogenized in digestion buffer. The liver was homogenized in digestion buffer, then mixed with chloroform and centrifuged. Total RNA in the upper aqueous phase was precipitated with isopropanol, rinsed with $75 \%$ ethanol, then resuspended in DEPC-treated water. To remove residual DNA, the RNA was treated with DNase (Sinaclon Bioscience, Tehran, Iran). The RNA was measured using a spectrophotometer. Only RNA with an absorbance ratio $($ A260/A280) $>1.9$ was used for the synthesis of cDNA. Total RNA was reverse transcribed into cDNA using PrimeScript ${ }^{m}$ RT Reagent Kit (Takara Bio Inc., Japan). The reverse transcription mix was heated to $85^{\circ}$ $\mathrm{C}$ for $5 \mathrm{~s}$ to inactivate reverse transcriptase and to denature the RNA and then stored at $-20^{\circ} \mathrm{C}$.

The levels of acetyl CoA carboxylase (ACC, EC 6.4.1.2), fatty acid synthase (FAS, EC 2.3.1.85), malic 
enzyme (ME, EC 1.1.1.40), lipoprotein lipase (LPL, EC 3.1.1.34), superoxide dismutase 1 (SOD1, EC 1.15.1.1), catalase (CAT, EC 1.11.1.6) and $\beta$-actin transcripts were determined by real-time reverse transcriptase (RT)-PCR using SYBR Premix Ex Taq ${ }^{\circ}$ II (TliRnase H Plus; Takara Bio Inc., Japan). We used $\beta$-actin as an endogenous standard to normalize the input load of cDNA among samples. Specific primers of the transcripts were designed with Primer-Blast (www.ncbi.nlm.nih.gov/tools/primer-blast/ index.cgi?LINK_LOC = BlastHome) are detailed in Table 2. PCRs were carried out in a real-time PCR cycler (Rotor Gene Q 6000, Qiagen, USA) in three replicates for each liver sample. One microliter cDNA was added to $10 \mu \mathrm{l}$ of SYBR $^{\circ}$ Premix Ex Taq II Mix with $1 \mu \mathrm{M}$ of each specific primer (total volume of $20 \mu \mathrm{l}$ ). The thermal profile was $95{ }^{\circ} \mathrm{C}$ for $30 \mathrm{~s}, 40$ cycles of $94{ }^{\circ} \mathrm{C}$ for $40 \mathrm{~s}, 64{ }^{\circ} \mathrm{C}$ for $35 \mathrm{~s}$ and $72{ }^{\circ} \mathrm{C}$ for $30 \mathrm{~s}$. Fluorescence was measured at the end of each phase. Gene expression data were normalized to $\beta$-actin. Data were analyzed using LinRegPCR software version 2012.0 (Amsterdam, Netherland) to obtain the threshold cycle number and reaction efficiency [16]. Relative transcript levels and fold changes in transcript abundance were calculated using efficiency-adjusted Paffl methodology [17].

\section{Statistical analysis}

Results were analyzed by ANOVA using SAS (2007) software in a completely randomized design. Treatment means were separated by t-test. In the cases of sampling within pens, data were subjected to a nested design.

\section{Results}

Mountain celery analysis shows remarkable contents of polyphenols $(102 \mathrm{mg} / \mathrm{g})$, flavonoids $(12.2 \mathrm{mg} / \mathrm{g})$ and phtalides, mainly ligustilides. Ligustilides accounted for $50 \%$ of total active products in the mountain celery.

Body weight gain and FCR responses were significantly $(P<0.05)$ improved in broilers when MC was included in diets during all feeding stages. However, feed intake only showed a significant decrease in the starter stage (Table 3).

The expression of genes responsible for hepatic lipogenesis, including ACC, FAS, ME, and LPL, significantly down-regulated in birds fed MC (Table 4). In contrast, antioxidant genes including SOD1 and CAT have been highly over-expressed in broilers fed MC (Table 4).

Broilers that received $\mathrm{MC}$ had significantly $(P<0.05)$ lower concentrations of total TAG, total cholesterol, LDL, malondialdehyde, and heterophil to lymphocyte ratio. Feeding MC caused a significant $(P<0.05)$ increase in HDL compared to the control group (Table 5).

\section{Discussion}

In general, live performance of the broilers in this study was lower compared to the expected performance outlined in the strain catalog (ROSS 308). This is due to the fact that the birds reared at high altitude region $(2100 \mathrm{~m})$, where atmospheric oxygen concentration was only 15$16 \%$. There is a direct relationship between broiler growth performance and atmoshpheric oxygen concentration [3]. Significant improvements in body weight gain and FCR associated with feeding birds MC are in line with results reported by Ahmadipour et al. [11]. Improved performance can be attributed to the naturally-occurring polyphenols in MC, which include flavonoids and non-flavonoids that exhibit a broad spectrum of beneficial biological properties such as growth-promoting, antioxidative, and immunocompetence $[8,18]$. Dietary inclusion of MC was

Table 2 Details of the primers used for quantitative real time PCR analysis of chicken mRNAs

\begin{tabular}{|c|c|c|c|}
\hline Target & Target Primers & PCR product (bp) & Accession No. \\
\hline \multirow[t]{2}{*}{$\beta$-Actin } & F:5'-AGCGAACGCCCCCAAAGTTCT-3' & 139 & NM_205518.1 \\
\hline & R:5'-AGCTGGGCTGTTGCCTTCACA-3' & & \\
\hline \multirow[t]{2}{*}{ FAS } & F:5'-GCTGGCTACAGTGGTGGACT-3' & 129 & NM_205155.2 \\
\hline & R:5'-CCACCTCGAACCACCAAAGC-3' & & \\
\hline \multirow[t]{2}{*}{ LPL } & F:5'-CTCCGATCCCGAAGCTGAGATG-3' & 106 & NM_205282.1 \\
\hline & R:5'-CTGTCCAGGAACCAGGTAGC-3' & & \\
\hline \multirow[t]{2}{*}{ ACC } & F:5'-CAACGAGTCGGGCTACTACC-3' & 146 & J03541.1 \\
\hline & R:5'-GGTCCTTGGTCACGTATGGG-3' & & \\
\hline \multirow[t]{2}{*}{ MAE } & F:5'-GGACCTCGAAGCCTTCATCC-3' & 77 & AF408407.1 \\
\hline & R:5'-GCCAGGTGTATGAGTCAGCC-3' & & \\
\hline \multirow[t]{2}{*}{ CAT } & F:5'-TGGCGGTAGGAGTCTGGTCT-3' & 112 & NM_001031215.1 \\
\hline & R:5'-GTCCCGTCCGTCAGCCATIT-3' & & \\
\hline \multirow[t]{2}{*}{ SOD1 } & F:5-CACTGCATCATTGGCCGTACCA-3' & 223 & NM_205064.1 \\
\hline & R:5-GCTTGCACACGGAAGAGCAAGT-3' & & \\
\hline
\end{tabular}


Table 3 Effects of dietary levels of mountain celery on broiler growth performance

\begin{tabular}{|c|c|c|c|}
\hline Variable & Control & Mountain celery $\left(7.5 \mathrm{gkg}^{-1}\right)$ & $P$-value \\
\hline \multicolumn{4}{|l|}{ Feed intake (g/bird) } \\
\hline $1-21$ days of age & $1052 \pm 8.4^{a}$ & $1007 \pm 10.9^{b}$ & 0.0127 \\
\hline $21-42$ days of age & $2873 \pm 44.3$ & $2839 \pm 32.4$ & 0.5499 \\
\hline $1-42$ days of age & $3925 \pm 36.1$ & $3846 \pm 28.5$ & 0.1262 \\
\hline \multicolumn{4}{|l|}{ Weight gain (g/bird) } \\
\hline $1-21$ days of age & $664 \pm 8.6^{b}$ & $704 \pm 7.3^{a}$ & 0.0081 \\
\hline $21-42$ days of age & $1334 \pm 18.3^{b}$ & $1488 \pm 7.1^{\mathrm{a}}$ & 0.0001 \\
\hline $1-42$ days of age & $1998 \pm 10.3^{b}$ & $2172 \pm 20.3^{a}$ & 0.0001 \\
\hline \multicolumn{4}{|l|}{ Feed conversion ratio } \\
\hline $1-21$ days of age & $1.58 \pm 0.009^{a}$ & $1.44 \pm 0.022^{b}$ & 0.0002 \\
\hline $21-42$ days of age & $2.15 \pm 0.008^{a}$ & $1.91 \pm 0.028^{b}$ & 0.0001 \\
\hline $1-42$ days of age & $1.96 \pm 0.011^{\mathrm{a}}$ & $1.77 \pm 0.026^{b}$ & 0.0001 \\
\hline
\end{tabular}

Means in the same row with different letters are significantly different

Values are mean $\pm \operatorname{SE}(n=5)$

associated with down-regulation of ACC, FAS, ME, and LPL in the liver. In avian species, the liver is the principal site of lipogenesis with a capacity 20 times greater than adipose tissue of equal weight [19]. The pathways involved in fatty acid synthesis in birds involve ACC catalyzing the conversion of acetyl-CoA to malonyl-CoA, and FAS catalyzing the formation of palmitate from one molecule of acetyl-CoA and 7 molecules of malonyl-CoA [20]. ME catalyzes the oxidative decarboxylation of malate to pyruvate and carbon dioxide, simultaneously generating nearly all of 14 molecules of NADPH required for palmitate biosynthesis [21]. Upon the biosynthesis of palmitate, fatty acids are transported to adipose tissue as TAG in the VLDLs, where extracellular LPL catalyses the hydrolysis of TAG so that fatty acids can be incorporated into the adipose tissue [22]. Down-regulation of these four key lipogenic enzymes by MC strongly suggests antihyperlipidemic effects as reflected in reduced levels of cholesterol, TAG, and LDL. The results of our study strongly suggest a strong nutrigenomic effect of $\mathrm{MC}$ on lipogenesis in birds, which may be associated with flavonoids and phthalides. A report on transcription-factor pathways mediating nutrient- gene interactions indicated ER (estrogen receptor), NFkB (nuclear factor $\mathrm{kB}$ ), and AP1 (activating protein 1) as transcription factors associated with flavonoids [23]. However, transcription factor associated with phthalide has yet to be determined. Mountain celery is a rich source of polyphenols $(102 \mathrm{mg} / \mathrm{g})$, flavonoids $(12.2 \mathrm{mg} / \mathrm{g})$ and phtalides, manily ligustilide.

Aqueous extract of celery has been reported to reduce total cholesterol and LDL in rats by lowering hepatic LPL activity [24] - an antihyperlipidemic effect linked with phthalides. The hypolipidemic effects of flavonoids have also been previously documented [25]. Bok et al. [26] indicated that polyphenols reduce the activity of HMG-CoA reductase, a key enzyme in the synthesis of cholesterol in mice. It has also been reported that polyphenols alter cholesterol homeostasis and increase LDL-receptor activity in human, which can increase LDL levels [27].

Stimulation of expression of SOD1 and CAT by MC suggests that the herb improves antioxidant defense system in birds, which could reduce levels of malondialdehyde (MDA). Previous research has shown that phtalides

Table 4 Effect of dietary mountain celery on lipogenic and antioxidant gene expression in broiler chickens measured at 42 days of age

\begin{tabular}{llll}
\hline Variable & Control & Mountain celery $\left(7.5 \mathrm{gkg}^{-1}\right)$ & $P$-value \\
\hline Acetyl CoA carboxylase & $0.025 \pm 0.007^{\mathrm{a}}$ & $0.003 \pm 0.001^{\mathrm{b}}$ & 0.0088 \\
Fatty acid synthase & $0.071 \pm 0.018^{\mathrm{a}}$ & $0.011 \pm 0.002^{\mathrm{b}}$ & 0.0049 \\
Lipoprotein lipase & $0.012 \pm 0.004^{\mathrm{a}}$ & $0.002 \pm 0.001^{\mathrm{b}}$ & 0.0189 \\
Malic enzyme & $0.029 \pm 0.009^{\mathrm{a}}$ & $0.002 \pm 0.001^{\mathrm{b}}$ & 0.0111 \\
Superoxide dismutase 1 & $0.0006 \pm 0.0001^{\mathrm{b}}$ & $0.014 \pm 0.002^{\mathrm{a}}$ & 0.0001 \\
Catalase & $0.0005 \pm 0.0001^{\mathrm{b}}$ & $0.005 \pm 0.001^{\mathrm{a}}$ & 0.0007 \\
\hline
\end{tabular}

$\overline{a, b, c}$ Means in the same row with different letters are significantly different Values are relative quantitative PCR (Target/ $\beta$-actin)

Values are mean \pm SE $(n=10)$ 
Table 5 Effect of dietary mountain celery on serum, blood, and carcass variables in broiler chickens measured at 42 days of age

\begin{tabular}{llll}
\hline Variable & Control & Mountain celery $\left(7.5 \mathrm{gkg}^{-1}\right)$ & $P$-value \\
\hline Total cholesterol $(\mathrm{mg} / \mathrm{dL})$ & $126 \pm 5.7^{\mathrm{a}}$ & $109 \pm 5.1^{\mathrm{b}}$ & 0.0006 \\
Total triacylglycerols $(\mathrm{mg} / \mathrm{dL})$ & $92.5 \pm 5.30^{\mathrm{a}}$ & $78.6 \pm 3.80^{\mathrm{b}}$ & 0.0003 \\
$\mathrm{HDL}(\mathrm{mg} / \mathrm{dL})$ & $30.6 \pm 2.75$ & $38.6 \pm 5.0$ & 0.0031 \\
$\mathrm{LDL}(\mathrm{mg} / \mathrm{dL})$ & $34.4 \pm 2.93^{\mathrm{a}}$ & $28.3 \pm 1.17^{\mathrm{b}}$ & 0.0001 \\
Malonedialdehyde ( $\mu \mathrm{mol} / \mathrm{L})$ & $3.57 \pm 1.31^{\mathrm{a}}$ & $1.59 \pm 0.77^{\mathrm{b}}$ & 0.0024 \\
Heterophils to Lymphocyte (\%) & $0.84 \pm 0.16^{\mathrm{a}}$ & $0.59 \pm 0.12^{\mathrm{a}}$ & $1.20 \pm 0.15^{\mathrm{b}}$ \\
Abdominal fat deposition (\%) & $1.80 \pm 0.27^{\mathrm{a}}$ & $1.87 \pm 0.19^{\mathrm{b}}$ & 0.0021 \\
Relative weight of liver (\%) & $2.25 \pm 0.21^{\mathrm{a}}$ & 0.0001 \\
\hline
\end{tabular}

${ }^{\mathrm{a}, \mathrm{b}}$ Means in the same row with different letters are significantly different

Values are mean \pm SE $(n=10)$

decrease MDA levels and increase the activities of the antioxidant enzymes such as glutathione peroxidise (GSH-Px) and SOD in mice [28]. Ligustilides (the major components of phtalides in $\mathrm{MC}$ ) have been reported to increase the activities of GSH-Px and SOD, which can prevent oxidative stress [29]. MDA is a biomarker of lipid oxidation is an index of oxidative stress in fat tissues. Decreased oxidative stress in birds fed MC can be associated with a significant reduction in the $\mathrm{H}: \mathrm{L}$ ratio, an index of stress in the chicken [30]. Taken together, feeding MC can suppress ROS production and alleviate oxidative stress in birds, and can be reflected by lower levels of MDA and H:L ratio.

Antihyperlipidemic effects of MC include reduced deposition of fat in the abdominal cavity. Abdominal fat is a crucial component of lipogenesis in birds because it grows more rapidly compared to other adipose tissues and is highly correlated to total body fat content in avian species. As it is easy to dissect and weigh, abdominal fat weight has been used extensively as an estimator of total body fat content in the chicken [31]. Reduction in abdominal fat deposition in birds fed MC indicates the strong antihyperlipidemic potency of the herb. Reduction in the proportion of liver weight to live body weight in chickens fed MC was in line with decreased lipogenesis associated with reduced abdominal fat. As the liver is the principal site of lipogenesis in chickens [19], a decline in its relative weight can account for lower lipogenesis associated with dietary inclusion of MC.

\section{Conclusion}

Feeding MC (Kelussia odoratissima) to broiler chickens led to a significant decrease in the expression of lipogenic enzymes and a significant increase in the expression of antioxidant enzymes, suggesting that this medicinal herb has potential to produce high quality low-fat chickens. These nutrigenomic effects are attributed to the phthalides, flavonoids, and polyphenols naturally in MC.

\begin{abstract}
Abbreviations
ACC: Acetyl CoA carboxylase; cDNA: Complementary DNA; DEPC-reated water: Diethylpyrocarbonate-treated water; FAS: Fatty acid synthase; H:L: Heterophil to lymphocyte; HDL: High-density lipoproteins; LDL: Lowdensity lipoproteins; LPL: Lipoprotein lipase; MC: Mountain celery; MDA: Malondialdehyde; ME: Malic enzyme; PCR: Polymerase chain reaction; TAG: Triacylglycerols
\end{abstract}

\section{Acknowledgements}

This study was financially supported by Shahrekord University, Shahrekord, Iran. The authors would like to sincerely appreciate Sherry Du from McMaster University, Hamilton, Canada for editing the manuscript.

\section{Funding}

This study was financially supported by Shahrekord University, Shahrekord, Iran.

\section{Availability of data and materials}

Date are ready upon request.

\section{Authors' contributions}

Study design: FK; Sample collection and chemical analysis: BA; Field and laboratory works: BA, FK; Data analysis: FK, HH; Manuscript preparation, BA, FK. All authors contributed to the revision of the manuscript, and approve of the final version of the article.

\section{Ethics approval and consent to participate}

The experiment was conducted in the Poultry Research Center of Shahrekord University, Shahrekord (2100 m above sea level), Iran. The study was carried out in accordance with the Guide for the Care and Use Committee of Shahrekord University. The authors acknowledge that they have considered 3Rs (https://www.nc3rs.org.uk/the-3rs) during the study design.

\section{Competing interests}

The authors declare that they have no competing interests.

\section{Publisher's Note}

Springer Nature remains neutral with regard to jurisdictional claims in published maps and institutional affiliations.

\section{Author details}

'Department of Animal Science, Shahrekord University, Shahrekord 88186-34141, Iran. ${ }^{2}$ Department of Basic Science, Shahrekord University, Shahrekord 88186-34141, Iran. 
Received: 28 March 2017 Accepted: 7 August 2018

Published online: 13 August 2018

\section{References}

1. Zuidhof MJ, Schneider BL, Carney VL, Korver DR, Robinson FE. Growth, efficiency, and yield of commercial broilers from 1957, 1978, and 2005. Poult Sci. 2014(93):2970-82.

2. Hocking PM. Unexpected consequences of genetic selection in broilers and turkeys: problems and solutions. Brit Poult Sci. 2014;55:1-12.

3. Khajali F, Wideman RF. Nutritional approaches to ameliorate pulmonary hypertension in broiler chickens. J Anim Physiol Anim Nutr. 2016:100:3-14.

4. Khajali F, Fahimi S. Influence of dietary fat source and supplementary atocopheryl acetate on pulmonary hypertension and lipid peroxidation in broilers. J Anim Physiol Anim Nutr. 2010;94:767-72.

5. Shahidi F, Ambigaipalan P. Phenolics and polyphenolics in foods, beveragesand spices: antioxidant activity and health effects -a review. J Func Food. 2015;18:820-97.

6. Pirbalouti A, Setayesh M, Siahpoosh A, Mashayekhi H. Antioxidant activity, total phenolic and flavonoids contents of three herbs used as condiments and additives in pickles products. Herb Polon. 2013;59:51-61.

7. Sajjadi SE, Shokoohinia Y, Moayedi N. Isolation and identification of ferulic acid from aerial parts of Kelussia odoratissima Mozzaf. Jundishapur J Nat Pharm Prod. 2012;7:159-62

8. Surai PF. Polyphenol compounds in the chicken/animal diet: from the past to the future. J Anim Physiol Anim Nutr. 2014;98:19-31.

9. Shojaei Z, Ebrahimi A, Salimi M. Chemical composition of three ecotypes of Kelussia odoratissima Mozzaf (Kelussia odoratissima). J Herb Spi Med Plant. 2011;17:62-8.

10. Ahmadi F, Kadivar M, Shahedi M. Antioxidant activity of Kelussia odoratissima Mozzaf /. In model and food systems. Food Chem. 2007; 105:57-64.

11. Ahmadipour B, Hassanpour H, Asadi E, Khajali F, Rafiei F, Khajali F. Kelussia odoratissima Mozzaf- a promising medicinal herb to prevent pulmonary hypertension in broiler chickens reared at high altitude. J Ethnopharmacol. 2015;159:49-54.

12. Rabbani M, Sajjadi S, Sadeghi M. Chemicalcompositionoftheessentialoil from Kelussia odoratissima Mozzaf. And the evaluation of its sedative and anxiolytic effects in mice. Clinics. 2011;66:843-8.

13. National Research Council, editor. Nutrient requirements for poultry. 9th revised ed. NY: National Research Council; 1994.

14. Association of Official Analytical Chemists. (AOAC). Official methods of analysis of the AOAC. 15th ed. Arlington; 1990.

15. Nair $\vee$, Turner GA. The thiobarbituric acid test for lipid peroxidation: structure of the adduct with malondialdehyde. Lipids. 1984;19:804-5.

16. Ruijter J, Ramakers C, Hoogaars W, Karlen Y, Bakker O, Van den Hoff M, Moorman A. Amplification efficiency: linking baseline and bias in the analysis of quantitative PCR data. Nucl Acid Res. 2009:37:1-12.

17. Dorak M. Real Time PCR Taylor \& Francis. Oxford: UK; 2006.

18. Kosmider B, Osiecka O. Flavonoid compounds: a review of anticancer properties and interactions with cis-Diamminedichloroplatinum(II). Drug Dev Res. 2004;63:200-11.

19. Steven L. Avian biochemistry and molecular biology. First ed. Cambridge: University Press; 1996. p. 46-56.

20. Annison EF. Lipid metabolism. In: Freeman BM, editor. Physiology and biochemistry of the domestic fowl. 1st ed. London: Academic Press; 1983.

21. Griffin H, Grant G, Perry M. Hydrolysis of plasma triacylglycerol rich lipoproteins from immature and laying hens (Gallus domesticus) by lipoprotein lipase in vitro. Biochem J. 1982;206:647-54.

22. Muller M, Kersten S. Nutrigenomics: goals and strategies. Nat Rev Genet. 2003:4:315-22

23. Tsi D, Das N, Tan B. Effects of aqueous celery (Apiumgraveolens) extract on lipid parameters of rats fed a high fat diet. Plant Med. 1995;61:8-21.

24. Anila L, Vijayalakshmi NR. Flavonoids from Emblica officinalis and Mangifera indica-effectiveness for dyslipidemia. J Ethnopharmacol. 2002;79:81-7.

25. Chen J, Li X. Hypolipidemic effect of flavonoids from mulberry leaves in triton WR-1339 induced hyperlipidemic mice. Asia Pac J Clin Nutr. 2007; 16:290-4.

26. Bok SH, Lee SH, Park YB, Bae KH, Son KH, Jeong TS, Choi MS. Plasma and hepatic cholesterol and hepatic activities of 3-hydroxy-3-methylglutaryl-CoA reductase and acyl CoA: cholesterol transferase are lower in rats fed citrus peel extract or a mixture of citrus bioflavonoid. J Nutr. 1999:129:1182-5.

27. Davalos A, Fernandez-Hernando C, Cerrato F, Martinez-Botas J, GomezCoronado D, Gomez-Cordoves C, Lasuncion MA. Red grape juice polyphenols alter cholesterol homeostasis and increase LDL-receptor activity in human cells in vitro. J Nutr. 2006;136:1766-73.

28. Kuang X, Du JR, Liu YX, Zhang GY, Peng HY. Postischemic administration of $z$-Ligustilide ameliorates cognitive dysfunction and brain damage induced by permanent forebrain ischemia in rats. Pharmacol Biochem Behav. 2008; 88:213-21.

29. Peng HY, Du JR, Zhang GY, Kuang X, Liu XY, Qian ZM, Wang CY. Neuroprotective effect of $Z$-ligustilide against permanent focal ischemic damage in rats. Biol Pharm Bull. 2007:30:309-12.

30. Khajali F, Karimi S, Qujeq D. Probiotics in the drinking water alleviate stress of induced molting in feed-deprived laying hens. Asia Aust J Anim Sci. 2008;21:1196-200.

31. Fouad AM, El-Senousey HK. Nutritional factors affecting abdominal fat deposition in poultry- a review. Asia Aust J Anim Sci. 2014;27:1057-68.
Ready to submit your research? Choose BMC and benefit from:

- fast, convenient online submission

- thorough peer review by experienced researchers in your field

- rapid publication on acceptance

- support for research data, including large and complex data types

- gold Open Access which fosters wider collaboration and increased citations

- maximum visibility for your research: over $100 \mathrm{M}$ website views per year

At BMC, research is always in progress.

Learn more biomedcentral.com/submissions 